www.jmscr.igmpublication.org

Impact Factor 5.84

Index Copernicus Value: 83.27

ISSN (e)-2347-176x ISSN (p) 2455-0450

crossref DOI:_https://dx.doi.org/10.18535/jmscr/v5i7.21

Journal Of Medical Science And Clinical Research

\title{
Functional Outcome of Patients with Proximal Humeral Fractures Managed by Proximal Humeral Inter Locking System Plating
}

\author{
Authors \\ Dr Manoj Kumar $\mathbf{R}^{1}$, Dr Ratheesh $\mathbf{E}^{2}$, Dr Sabarisree $\mathbf{M}^{3}$ \\ ${ }^{1}$ Additional Professor in Orthopaedics, Govt Medical College, Thiruvananthapuram \\ ${ }^{2}$ Junior resident in Orthopaedics, Govt Medical College, Thiruvananthapuram \\ ${ }^{3}$ Associate Professor (CAP) in Orthopaedics, Govt Medical College, Thiruvananthapuram \\ Corresponding Author \\ Dr Sabarisree M \\ Associate Professor (CAP) in Orthopaedics, Govt Medical College, Thiruvananthapuram
}

\begin{abstract}
Background: Our study is planned to evaluate functional outcome of patients with proximal humeral fractures managed by proximal humeral inter locking system plating in view of range of movement, possible returns of basic functions around shoulder girdle, radiological outcome and resultant remaining disability in the course of healing and after completion of healing.

Materials and Methods: one year study and each patient is followed up for 6 months after the procedure. 42 patients with proximal humerus fractures were managed With locking plate all of them completed mean follow up 6 months and evaluated using constant murley scoring system.

Results: In 42 patients 18 were male and 23 were females, $40.5 \%$ of patients were above 60 years of age common mode of injury was fall from height about $54.8 \%$, and one patient had one part fracture, 18 had 2part fractures, 18 patients had 3-part fractures, and 5 patients had 4-part fractures. After 6 month follow up, a mean Constant score $71.6 \%$ was achieved. Outcomes were excellent in 45.2\%, good in 19\%, fair in $31.0 \%$ while poor in $4.8 \%$. The Constant score was poorer for Neer type IV fractures as compared to other types. The most frequently occurring complications in our patients were infection 38.1\%, avascular necrosis $14.3 \%$, no improvement in movement after 6 month $11.9 \%$

Conclusion: Proximal humeral locking plate is an exciting new method of osteosynthesis for complex proximal humerus fractures allowing early mobilization, good functional outcome and is a superior treatment option to hemiarthoplasty.

Keywords: Proximal humerus locking plate, constant score.
\end{abstract}

\section{INTRODUCTION}

Proximal humeral fractures are now recognized as an increasingly common fracture, accounting for $4 \%-5 \%$ of all fractures ${ }^{1}$ and $45 \%$ of all humeral fractures $^{2}$. It is the third most common fracture, in people above 65 years of age, after fractures of the hip and distal radius ${ }^{3}$. These fractures have a bimodal distribution occurring either in young people following high energy trauma or in those older than 50 years with low velocity injuries like simple fall.

Proximal humeral fractures are common fractures 
in the elderly population $\& 80 \%$ are treated nonoperatively. Neers classification for proximal humeral fractures - 2,3 and 4 part fractures are managed by operative fixation 4,10

So many techniques are used for fracture fixation like, closed reduction and percutaneous K-wire fixation,open reduction and fixation with bone sutures, tension band wiring, circulating wiring ,t plate, intramedullary nailing 5 , locking plates, shoulder arthroplasty, philos plate

Loosening or failure of the implant and nonunion are possible complications of surgery in humeral fractures. There is still no treatment that can be the golden standard in this fractures ${ }^{[6-8]}$. In order to decrease the high complication rates of proximal humeral fractures, the AO/ASIF group developed the PHILOS (The Proximal Humeral Internal Locking Osteosynthesis ${ }^{16}$ ) plate (Synthes, Stratec Medical ltd, Mezzovico Switzerland); an internal fixation system that enables angled stabilization with multiple interlocking screws. PHILOS is increasing use now because of minimal soft tissue dissection, better fracture fixation in elderly osteoporotic bones, provides axial and angular stability, reducing the risk of fracture displacement however, there are few prospective studies available that actually evaluate the results of this technique or report on the treatment related complications. this study was planned to evaluate the outcome of proximal humerus fractures managed with PHILOS plate after approval by the Institutional EthicalBoard.

\section{MATERIALS AND METHODS}

This prospective interventional study was conducted in the department of orthopedics at a tertiary care centre, Trivandrum from December 2015 to January 2017. Total 42 consecutive adult patients of either sex with displaced proximal humerus fractures that met the criteria for operative treatment as outlined by Neer i.e. an angulation of articular surface of more than 45 degrees, a displacement between the major fracture fragments more than $1 \mathrm{~cm}$ or a fracture with valgus impaction were included in the study. Inclusion criteria patients aged 20-70 years with closed proximal humeral fractures 2, 3 and 4 part fractures of the neer classification) managed operatively with philosplating.

Exclusion criteria open fractures, pathological fractures, Fractures managed conservatively and with other methods.All the cases were assessed clinically, resuscitated (if required) and treated accordingly. All routine investigations and preoperative $\mathrm{X}$ rays were sent Classification of fracture was done using Neer's classification system. ${ }^{9}$

After all preoperative investigations and anaesthesia fitness surgery performed under general anaesthesia, in supine position with one small sand bag below the inters capular area, on a radiolucent table under general anaesthesia using the anterior deltopectoral approach. The cephalic vein was retracted laterally and preserved. according to the type of fractures the fracture reduction done.and temporary $\mathrm{k}$ wire fixation done and with $\mathrm{c}$ arm the reduction were assessed.the greater tuberosity fractures are reduced either with sutures which tags them or wth $\mathrm{k}$ wire. Obvious caution taken to get a good medial calcar continuity after getting adequate reduction exact size philos plate was used for fixation. Which was fixed primarily by $\mathrm{k}$ wire and then with $3.5 \mathrm{~mm}$ and $4 \mathrm{~mm}$ screws. On the anteroposterior view, the plate was ideally placed $8 \mathrm{~mm}$ distal to the superior tip of the greater tuberosity; from the lateral view, the plate was centred against the lateral aspect of the greater tuberosity. An adequate gap was left between the plate and the biceps tendon to prevent disruption of the anterior humeral circumflex artery or entrapment of the tendon The initial screw was then placed in the elongated hole in the humeral shaft (in classic 3 or 4 part fractures), so that the height of the plate could be adjusted. After achieving the appropriate fracture reduction and plate position, the locked $4 \mathrm{~mm}$ cancellous screws were inserted into the humeral head. At least three to five distal shaft screws were inserted. A 
final fluoroscopic image was taken to ensure adequate reduction and proper medical support. Rotator cuff, capsule and subscapularis muscle tears/avulsions were repaired meticulously. The wound was closed in layers and a suction drain will beinserted.

Active assisted and passive exercises were used during the first two weeks, and 3 weeks later active motion was started. On the 8th postoperative week, daily activities were allowed. Patients were followed up on OPD basis at 2 weeks at first postoperatively then after every month till 6 month. At every follow up, patients were assessed clinically for shoulder stability and range of motion and radio graphically checked for the progress of fracture healing. Radiographic union was defined as bridging trabeculation and callus formation across the fracture site in the absence of hardware breakage or cut-out or signs of implant failure. The complications were also documented. Evaluation of results were done on basis of scoring system given by Constant and Murley score, the scoring system of which comprises four parts: pain, power, activities of daily living and range of movement.. The Constant score was graded as poor (55 points), moderate (56-70), good (71-85) or excellent (86100)

\section{RESULTS}

The mean age of our 42 patients was 48.81 (20-70), with a female: male ratio of 1.33:1(24:18), 17 patients belong to age group more than 60 years suggesting a strong relation of proximal humerus with age related osteoporosis.

Mechanism of injury injury road traffic accident $45.2 \%$ fall from height $54.8 \%$. 16 casesinvolved the dominant right side with $38.1 \%$ and rest $26(61.9 \%)$ left side was involved .According to NEER'S classification the percentage of fractures were part one $2.4 \%$,part two $42.9 \%$,part three $42.9 \%$ and part four $11.09 \%$.Along with the fracture shoulder dislocation present in 38.1\%(16)had hypertension, and 47.6(20) patients had diabetes mellitus,35.7\%(15) had other bony injury along with proximal humeral fractures. Post operative infection was present in $33.3 \%$ (14), primary bone graft was done in 31\%(13)cases. Onpost operative follow up $14.3 \%$ (6) patients dealt with avascular necrosis of head of humerus

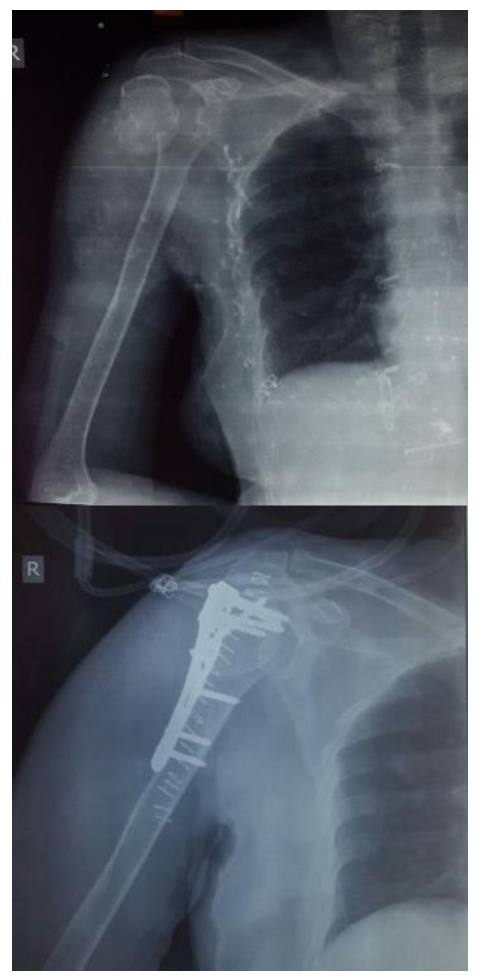

Fractures united at an average of 12-20 week time. 6 patients developed nonunion due to avascular necrosis in them one patient's head screw and plate pulled out. Table 1 and table 2 shows Constant scores of the patients at the final follow up visit according to fracture types and age respectively. Overall the functional outcome was found to be good to excellent in $64.2 \%$ of our patients however only 2 patients had worst out come in six month follow up. The mean Constant score achieved was $71.6 \%$ (range, 1780 ). We found that patients with Neer type two and three fractures had the highest Constant scores while patients with Type IV had the lowest Constant scores. Patients less than 60 years of age group showed better response, And painless range of movement is increased in 88.1\%(37).patients.

\section{DISCUSSION}

In our study patients suffered from more complex fractures are after high velocity injuries such as road traffic accident. Western literature has 
shown proximal humerus fractures to be more common in elderly females 10 . In respect to majority of studies in western literature that consider low energy falls as a more common cause for proximal humerus fractures, our study also had $54.8 \%$ patients with fall from height, which was the major part., and most of them due to osteoporosis due to old age and premenopausal age, in young age the cause is mostly due to raod traffic accident.

Table 1 shows the outcome of patients with respect to part of frctures.We got excellent result with part 2 and three fractures.

Table 2 denotes the outcome with respect to sex of the individual in these $70.6 \%$ outcome for men and for females $63.5 \%$,it may be due to most of the fractures in females occurs during their premenopausal age group, and good healing and bone stock will be less due to osteoporosis

Table 3 denotes the age wise outcome of the patients less than 40 years of age got mean score of $83.3 \%$

Table 1 Functional outcome on the basis of Constant score at the last follow up visit.

\begin{tabular}{|l|c|}
\hline $\begin{array}{l}\text { Neer's Type of } \\
\text { fracture }\end{array}$ & Mean Constant score \\
\hline Part 2 fracture & $78.1 \%$ \\
\hline Part 3 fracture & $62.3 \%$ \\
\hline Part 4 fracture & $58.1 \%$ \\
\hline
\end{tabular}

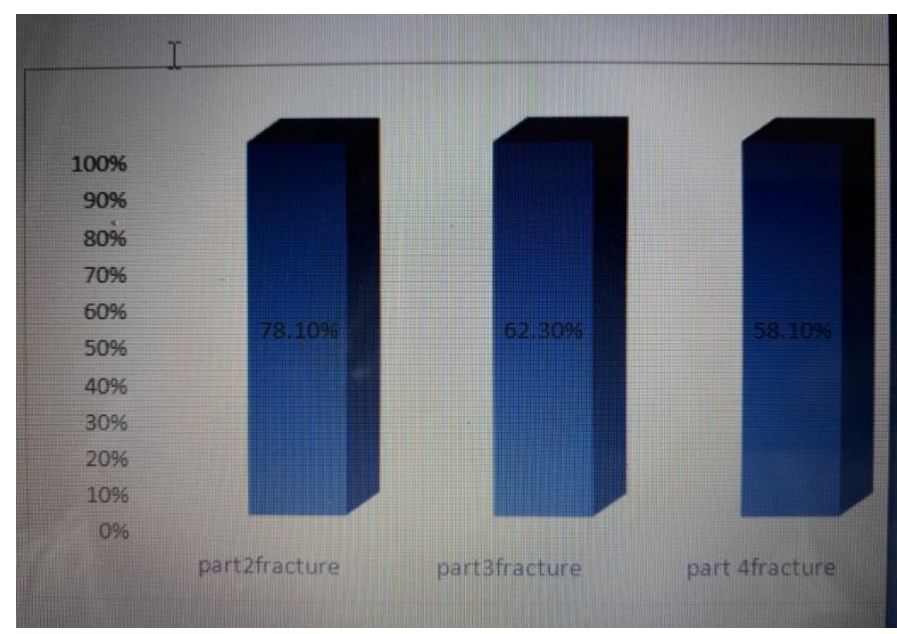

Table 2 Constant score at follow up visits according to the sex of patient.

\begin{tabular}{|l|l|}
\hline Sex & Mean constant score \\
\hline Male & $70.6 \%$ \\
\hline Female & $63.5 \%$ \\
\hline
\end{tabular}

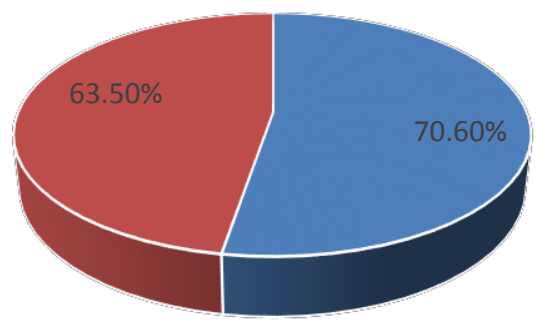

Table 3 Constant score at follow up visits according to the age of patient.

\begin{tabular}{|l|c|}
\hline Age & Mean constant score \\
\hline $20-40$ years & $83.3 \%$ \\
\hline $40-60$ years & $69.1 \%$ \\
\hline$>60$ years & $61.9 \%$ \\
\hline
\end{tabular}

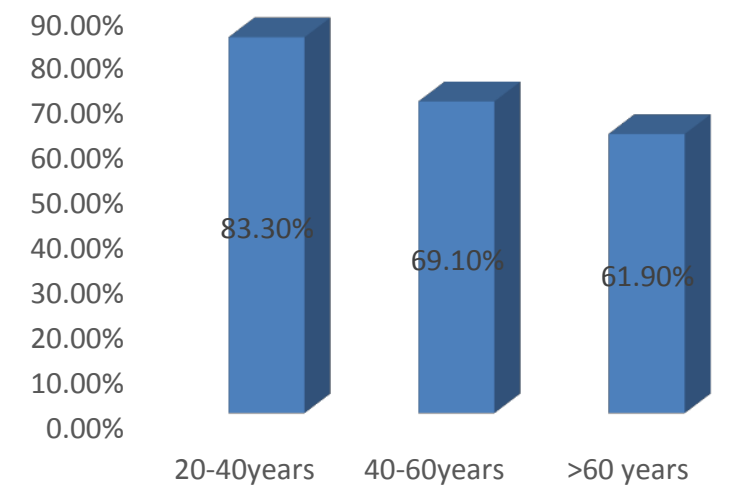

The proximal humeral fractures are most dreadful fractures in elderly. Due to osteoporosis and in woman perimenopausal age group these fractures are most common. Road traffic accident is becoming the most common in younger age group, according to our study RTA $45.2 \%$ and fall from height is about $54.8 \%$. The surgical management of proximal humeral fractures is always challenging. PHILOS will give a minimally invasive low profile system for the fixation and can reduce the complications like avascular necrosis and can improve the range of 
movement and standard of daily living

In our study we could achieve a mean Constant Murley score of $71.6 \%$ in 6 month follow up study of a pateint. Our results were somehow comparable with the results those reported in the western literature.

Various studies had reported varying results. Thyagarajan $^{12}$ et al in their study on 30 patients showed an overall average Constant score of 57.5. The mean age in this series was 58 years (range 1992 years) and fractures were Neer's 2-part, 3-part, and 4- part fractures. In one prospective study, mean constant score was 68.31 in 19 patients. Kettler $^{13}$ et al reported a Constant- Murley score between 52 to 72 points after ORIF with the PHILOS plate. Hente ${ }^{14}$ et al reached a mean Constant-Murley score of 55 points in these specific fracture types, which was lower than for fractures without dislocation. Constant-Murley score of different studies are difficult to compare.

However, the systematic review by Thanasis 15 et al reported an overall Constant score of 74.. and most of other studies have reported good functional outcomes and recommended the use of locking plates for proximal humerus fractures especially in elderly patients with poor bone quality. This leads us to believe that application of locking plate technology for proximal humerus fractures has a steep learning curve and appropriate surgical technique is very important for achieve good functional outcome. The constant score of our study is little higher side may be because of young individuals are more in our study and most of the fractures comes to the category ofpart two andthree In our study also the mean Constant score for 4-part fractures was $58.1 \%$ which were inferior as compared to 2-part and 3-part fractures $(78.1 \%$ and $62.3 \%$ respectively). This result is comparable to the one prospective study in which the mean Constant score for 4-part fractures was significantly inferior to other types. These results are expected as these fractures are more complex and open reduction and internal fixation is tougher. We found difference in outcome between patients of age group less than or more than 60 years of age. Patients less than 60 years of age group showed better response. Similar findings have been reported by Aggarwal et al who found the Constant scores to be higher in younger patients as compared to older patients $(>65)$

In our study younger age group below 60 years are more 25 patients. The our study $20-40$ years $83.3 \%$ and $40-60$ years has $69.1 \%$ and over 60 years $61.9 \%$

Post operatively, various complications were observed. Infections are more commonest complications. $38.1 \%$ (16) had infections and three of them under went resurgical procedure for putting antibiotic bead and infection subsided for two and further bead removal done.one patient had severe dischagr from the site and implant removal done after 5 month. 14.3\%(6)patients had avascular necrosis of shoulder and had severe painful shoulder movement and one patient had Implant cut out for which implant removal done and planned for hemiarthroplasty $^{17}$. Avascular necrosis ${ }^{18}(\mathrm{AVN})$ is one of the most dramatic complications requiring reoperation. 4 patients (9\%) was of 3 part fractures and 2 patient (4\%) was of four part fractures. All are planned for hemiarthroplasty after the removal of implant. As per the published literature, the chances of AVN of the shoulder are directly proportional to the severity of the injury. The risk of osteonecrosis increases if the anterolateral branch of the anterior humeral circumflex artery is damaged. Utmost care should be taken while exposing the biceps tendon in the bicipital groove

The plate removal was necessary for two patients within six month follow up. one with severe infections and other with severe osteonecrosis

The limitation of this study is lack of a control group and less follow up period and we do not evaluate any patient characteristics which can be risk factors for failure except for diabetes and hypertension 


\section{CONCLUSION}

Fixation of proximal humerus fractures with proximal humerus locking plates is associated with satisfactory functional outcomes in 2-part and 3part fracture. The most good and minimally invasive method and plate osteosynthesis is used commonly now. The chance of reoperations is too high when complications like osteonecrosis arise. Inadequate positioning of the implant resulted in reduced functional outcome.

Hence, to improve functional results, correct placement of the plate with correct length screw and near perfect reduction need to be there. Adequate surgical skills and surgeon's experiences with the surgical technique are necessary to achieve correct implant fixation and avoid these intraoperative errors.

Moreover patient's risk for complications should be evaluated more individually and taken into consideration for the concept of treatment..

\section{BIBLIOGRAPHY}

1. J. M. Muthuuri Outcome Of Plate Osteosynthesis In Management Of Proximal Humeral Fractures In Adults. African Orthopaedic Journal, September 2010 Vol. 4:37-40.

2. Spence RJ. Fractures of the proximal humerus. CurrOpinOrthop 2003;14:269-80.

3. Baron JA, Barrett JA, Karagas MR. The epidemiology of peripheral fractures. Bone 1996;18(3):209S-13S.

4. Adedapo AO, Ikpeme JO: The results of internal fixation of three- and fourpart proximal humeral fractures with the Polarus nail, Injury32:115,2001

5. Agel J, Jones CB, Sanzone AG, et al: Treatment of proximal humeral fractures with Polarus nail fixation, J Shoulder Elbow Surg 13:191,2003

6. Agudelo JF, Schürmann M, Stahel P, et al: Analysis of efficacy andfailure in roximalhumerus fractures treated with locking plates, J OrthopTrauma

7. Robinson CM, Page RS. Severely impacted valgus proximal humeral fractures:

Results ofoperative

8. treatment. J Bone Joint Surg Am 2003, 85:1647-55.

9. Wanner GA, Wanner-Schmid E, Romero J, Hersche O, von Smekal A, Trentz O, Ertel W. Internal fixation of displaced proximal humeral fractures with two onethird tubular plates. JTrauma

10. Park MC, Murthi AM, Roth NS, Blaine TA, Levine WN, Bigliani LU. Two-part and three-part fractures of the proximal humerus treated with suture fixation. J Orthop Trauma 2003,17:319-25.

11. Neer CS. Displaced proximal humeral fractures-II. Treatment of three-part and four-part displacement. J Bone Joint Surg Am 1970,52(6)

12. Chu SP, Kelsey JL, Keegan TH, Sternfeld B, Prill M, Quesenberry CP, Sidney S. Risk factors for proximal humerus fracture. Am $\mathrm{J}$ Epidemiol 2004,15(160):360-7.

13. Thyagarajan DS, Haridas SJ, Jones D, Dent C, Evans R, Williams R. Functional outcome following proximal humeral interlocking system plating for displaced proximal humeral fractures. Int $\mathbf{J}$ Shoulder Surg.2009;3(3):57-62.

14. Kettler M, Biberthaler P,Braunstein V, Zeiler C, Kroetz M, MutschlerW. [Treatment of proximal humeral fractures with the PHILOS angular stable plate. Presentation of 225 cases of dislocated fractures]. Unfallchirurg German 2006, 109:1032-40

15. Hente R, Kampshoff J, Kinner B, Fuchtmeier B, Nerlich M. [Treatment of dislocated 3- and 4- part fractures of the proximal humerus with an anglestabilizing fixation plate][in German]. Un- fallchirurg.2004;107:769-82.

16. Thanasas C, Kontakis G, Angoules A, Limb D, Giannoudis P. Treatment of proximal humerus fractures with locking 
plates: a systematic review. J Shoulder Elbow Surg. 2009;18(6):837-44.

17. Brorson S, Frich LH, Winther A, Hrobjartsson A: Locking plate osteosynthesisnin displaced 4-part fractures of the proximal humerus: a systematic review of benefits and harms, ActaOrthop 82:475,2011.

18. Cadet ER, Ahmad CS: Hemiarthroplasty for three- and four-part proximal humerus fractures, J Am AcadOrthopSurg 20:17,2012.

19. Clavert P, Adam P, Bevort A, et al: Pitfalls and complications with locking plate for proximal humerus fractures, J Shoulder Elbow Surg 19:489,2010.

20. Bansal V, Sohal HS, Bhoparai RS. Philos Plate in Proximal Humerus Fracture-Its Functional Outcome and Complications. International Journal of Orthopaedics 2015; 2(2): $317-322$ 